\title{
Do Orientation-Based Differences in Nestbox Temperature Cause Differential Ectoparasite Load and Explain Patterns of Nest-Site Selection and Offspring Condition in Great Tits?
}

\author{
Anne E. Goodenough, ${ }^{1}$ Simon L. Elliot, ${ }^{1,2}$ and Adam G. Hart ${ }^{1}$ \\ ${ }^{1}$ Department of Natural and Social Sciences, University of Gloucestershire, Francis Close Hall Campus, Swindon Road, \\ Cheltenham, Gloucestershire GL50 4AZ, UK \\ ${ }^{2}$ Department of Entomology, Federal University of Viçosa, 36570-000 Viçosa, MG, Brazil
}

Correspondence should be addressed to Anne E. Goodenough, aegoodenough@glos.ac.uk

Received 5 August 2011; Revised 14 October 2011; Accepted 14 October 2011

Academic Editor: Marcel Eens

Copyright ( $) 2011$ Anne E. Goodenough et al. This is an open access article distributed under the Creative Commons Attribution License, which permits unrestricted use, distribution, and reproduction in any medium, provided the original work is properly cited.

\begin{abstract}
Nest ectoparasites have been linked previously to patterns of nest-site choice and breeding success in birds. Recent research has shown nestboxes facing south-southwest are occupied less frequently by great tits (Parus major) than identical boxes facing other directions, and are associated with reduced offspring condition. Here, we investigate the hypothesis that these findings are due to ectoparasite load being directionally nonuniform, possibly because of nonuniformity in nestbox internal temperature. Nests contained, in order of prevalence, hen fleas (Ceratophyllus gallinae), haematophagous blowflies (Protocalliphora spp.), biting lice (Ischnocera), and ticks/mites (Acari). Although southwest-facing nestboxes were significantly warmer than other boxes, there was no directional difference in total ectoparasite load or abundance of particular species. Similarly, there was no relationship between abundance of any ectoparasite species (either per-nest or per-chick) and avian offspring condition determined using wing length or relative mass. We discuss several possible, nonmutually exclusive, explanations for this, including compensatory responses, costs of parasitism being transferred to parents, and condition-dependent effects.
\end{abstract}

\section{Introduction}

Birds' nests are occupied by more than just birds: they are an important habitat for a diverse invertebrate fauna. The nest structure becomes a miniature ecosystem of specialised nest-dwelling arthropods, comprising both ectoparasitic and free-living species $[1,2]$. However, although arthropods are a common component of a breeding bird's environment, ectoparasite abundance often exerts a strong influence on nestsite choice [3]. For example, the abundance of the haematophagous tropical fowl mite (Ornithonyssus bursa) influences nest-site choice in semicolonial barn swallows (Hirundo rustica) [4] while great tits (Parus major) avoid nest sites heavily infested with hen fleas (Ceratophyllus gallinae) [5]. Experimental studies on pied flycatchers (Ficedula hypoleuca) have shown preferential selection of nest sites where old nests have been removed to eradicate overwintering ectoparasites [6].
Avoidance of nest sites with high ectoparasite loads appears to be a behavioural response to avoid, or at least reduce, the negative effect of parasitism on the survival and condition of offspring [7]. Blood loss to haematophagous ectoparasites can result in anaemia and weight loss (e.g., $[8,9]$ ) while ectoparasitism can also cause disease, either through ectoparasites acting as vectors $[10,11]$, or via postparasitism microbial infection of puncture or scratch wounds [12]. As a result, chicks exposed to high ectoparasite loads while in the nest may suffer stunted growth, reduced weight, and decreased prefledging survival. This has been demonstrated in great tit nestlings parasitised by hen fleas $[13,14]$ and pied flycatcher chicks parasitised by haematophagous blowfly larvae (Protocalliphora spp.) [15]. When abundant, nest-dwelling ectoparasites can reduce chick condition to the extent that postfledging survival is affected, as found in marsh tits (Poecile palustris) [16]. However, although adaptive nest-site selection could be a useful strategy to reduce parasite loads 
and their negative effects, it is not always feasible. In some cases, there may be no other "better" nest sites available (at least within the distance that search costs associated with finding them are outweighed) while in other cases ectoparasites (e.g., blowflies) may only enter nests after chicks hatch, such that load cannot be anticipated during nest-site selection.

Nest ectoparasite load could be influenced by several factors. Abiotic factors include temperature and humidity of nests (which, in turn, are influenced by factors such as latitude, year, time in the breeding season, brood size, and bird body temperature), as well as the amount and type of nest material $[17,18]$. Biotic factors include interactions between nest arthropod species, both positive (facilitation or mutualism) and negative (inhibition or competition) [2]. For example, poultry red mites (Dermanyssus gallinae) are depredated by cosmopolitan nest mites (Androlaelaps casalis), such that their abundance in starling (Sturnus vulgaris) nests partially depends on the abundance of this predator [19]. Characteristics of nest sites thus have the potential to affect ectoparasite abundance, either directly (through influence on abiotic conditions) or indirectly (through the changes that modified abiotic conditions might have on the nest-dwelling arthropod community). However, although it has been noted that some nestboxes consistently support more ectoparasites than others (M. Stenning personal communication), the relationships between nest-site characteristics and ectoparasite load has not been fully investigated. This is despite the fact that such relationships could be important causal factors in otherwise unexplained patterns of nest-site choice and breeding success.

Previous research in a British oak woodland over a 15year period (1990-2004), revealed that the frequency of nestbox occupation correlates with orientation in the great tits. Specifically, nestboxes facing south-southwest are used less frequently than boxes facing other directions [20]. Research at the same site in 2006 showed that nestboxes oriented south-southwest are also significantly warmer than boxes facing other directions and are associated with lower offspring condition [21], suggesting that the birds are demonstrating adaptive nest-site choice. However, although the ultimate cause of nest avoidance would seem to be responsiveness by parents to factors influencing offspring condition, the proximate explanation-what actually causes reduced offspring condition in southwest-facing boxes-is still unclear. Insights into mechanisms behind observed behaviour are ecologically important, and could aid conservation efforts by maximizing the effective placement of nestboxes. We hypothesise that differences in nest-site selection and offspring condition are due to high parasite loads in boxes as a result of orientation-induced differences in nestbox microclimate. There is already some evidence that abundance of ectoparasites (hen fleas) may be influenced by orientation in Pied Flycatcher nestboxes [22], although possible reasons for this have not been considered. In this study, we test the following hypotheses: (1) that nest ectoparasite load is directionally nonuniform (specifically, that it is higher in nestboxes facing south-southwest given the higher temperature of such boxes at this particular study site); (2) that high ectoparasite load has a detrimental impact on offspring condition in great tits, such that avoidance of parasite-related fitness costs is responsible for nonuniform nest-site selection.

\section{Methods}

2.1. Study Area. This study was undertaken in 2006 at Nagshead Nature Reserve (Gloucestershire, UK): the same site where the relationship between nestbox orientation and occupation was quantified for great tits using data from 1990 to 2004 [20] and where the relationship between orientation and great tit offspring condition was researched, also in 2006 [21]. To avoid introduction of confounding factors, all nestboxes included in the study were made of $13 \mathrm{~mm}$ plywood and were the same size (rectangular with a sloping roof; internal measurements: $110 \mathrm{~mm}$ width, $170 \mathrm{~mm}$ depth, $210 \mathrm{~mm}$ midpoint height; hole size $28 \mathrm{~mm}$ ). They were placed $\sim 3 \mathrm{~m}$ above the ground and had been thoroughly cleaned out after the preceding breeding season to remove old material. The use of nestboxes, and success of the occupants, was monitored throughout the breeding season by the Royal Society for the Protection of Birds (RSPB).

2.2. Study Design. The orientation of all boxes used by great tits in $2006(n=49)$ was determined using a line-of-sight compass (Silva Voyager 8040 ) with a resolution of $1^{\circ}$. Ten boxes facing south-southwest (180-269 $)$ were occupied. Each of these boxes was paired with another nestbox occupied by great tits facing, as nearly as possible, the diametrically opposite direction. Pairing took account of two potentially confounding variables: (1) the number of young at day 15 after hatching ( \pm one chick if absolutely necessary; applied to 3 pairs) and (2) time in the season (hatching date \pm one day) When there was a choice of possible nestboxes with which to pair a south-southwest box after meeting these criteria, the nearest box was selected. A paired study design was chosen as being the most robust strategy given statutory restrictions on the number of nests that could be removed for parasite analysis (see below).

2.3. Avian Offspring Condition. Biometrics of chicks $(n=$ 93) from each nest $(n=20)$ were taken 15 days after hatching. This was as near to fledging as possible while mitigating the risk of disturbance-induced premature fledging. Wing length was measured to the nearest $1 \mathrm{~mm}$ with a stopped ruler using the flattened-straightened wing method [23]; this is the best single correlate of condition in birds [24]. Weight was taken to $0.1 \mathrm{~g}$ using a spring balance (Pesola, Switzerland) with the bird restrained in a polythene cone. Calculation of relative mass - useful in studies of chicks - was undertaken by dividing wing length by weight. All biometrics were taken by the same trained recorder.

2.4. Nest Parasite Load. The nest structure was removed from each nestbox within $24 \mathrm{hrs}$ after fledging, before ectoparasites began leaving the nest [25]. Since removing nest material in the UK is only permitted between August and January (under the general licence WLF100068), nest removal was undertaken under a site-, species-, and year-specific licence from English Nature (number: 20060590). This allowed 
immediate postfledging removal of 20 great tit nests at the study site in 2006. Once removed, the nest was placed in an air-tight polythene bag. Feather dust and hen flea larvae remaining in the nestbox were collected by aspiration with a pot pooter (Alana Ecology, Shropshire, England), using suction provided by a battery-powered miniature vacuum cleaner (Halloa KBC-1, Halloa Enterprise, Taiwan).

Once in the laboratory, nests were frozen to $-28^{\circ} \mathrm{C}$ for at least $72 \mathrm{hrs}$ to kill and preserve ectoparasites [26]. Nest material was then sieved to remove feather dust [17], which was searched using a paint brush [27]. The remaining nest material was thoroughly searched under a Nikon SMZ800 dissection microscope using tweezers to pull apart the nest structure [11]. Arthropods were extracted using entomological forceps and preserved in 70\% (v/v) ethanol with 3\% $(\mathrm{w} / \mathrm{v})$ glacial acetic acid (to prevent specimen shrinkage) and $3 \%(\mathrm{v} / \mathrm{v})$ glycerol (to prevent specimen hardening) [25]. Arthropods were identified under the dissection microscope using standard keys.

2.5. Statistical Analyses. To quantify any differences in total ectoparasite abundance (and abundance of specific ectoparasite species and life stages) according to nestbox orientation category, independent $t$-tests were used. Although a paired sampling design was used to ensure confounding variables did not cause bias, parasite load was not compared using paired $t$-tests as different boxes were involved.

To correlate ectoparasite load and offspring quality was more complex. In most biometric studies, each individual can be considered independent of others in the sample. Here, however, chicks from one nestbox were clearly not independent of one another, and it was not appropriate to enter the measurements from all individuals directly into an analysis without accounting for this replication. Two analytical approaches were used, each accounting for replication in a different way. In the first approach, mean withinbrood offspring quality was calculated for each measure of condition (wing length or relative mass) to give two estimates of offspring quality per brood. This controlled for replication since only one value was entered per nest. Separate multiple linear regression analyses (MLRs) were then undertaken for wing length and relative mass, with, in both cases, the abundance of each ectoparasite species being entered as separate predictor variable. Full models were created using the abundance of all ectoparasite species, and reduced models were attempted using a stepwise procedure with Akaike's information criterion (AIC) as a method of model reduction (following [28]) to achieve parsimony and maximise understanding of bird-parasite interactions. Initially, the load of each ectoparasite species was quantified on a per-chick basis (i.e., the total nest abundance divided by the brood size). This is often considered more rigorous than using nest abundance [29], but assumes that all chicks are equally parasitised. Empirical testing of this (e.g., [30]) has suggested it can be erroneous (the "tasty chick" hypothesis [30]), so here two full and two reduced MLRs were undertaken for wing length and relative mass, respectively, the first using per-chick ectoparasite burden and second using per-nest ectoparasite abundance (following [31]). The second analytical approach utilised type I general linear mixed modelling (GLMM), whereby the condition of all chicks was entered as the dependent variable with a random factor of nestbox controlling within-brood pseudoreplication. Two GLMM models were created; one for each condition proxy. In both cases, the nestbox load of each ectoparasite species was added as a separate fixed factors with abundance categorised using an ordinal scale based on the four quartiles (so boxes with a very high level of parasites $(75-100 \%$ quartile $)=4$, a medium high level $(50-74 \%$ quartile $)=3$, a medium low level $(25-$ $49 \%$ quartile $)=2$ and a very low quartile $(0-24 \%$ quartile) $=1$ ). Simultaneous use of the MLR approach, which maximised retention of the parasite data, and the GLMM approach, which maximised retention of offspring data, ensured robust data analysis using methods that are complementary to one another (following [21]).

In all MLR and GLMM analyses, abundance of larval hen fleas was included in addition to the abundance of adult hen fleas (as per [17]) as a separate variable. This was done because although larvae do not parasitise directly, and do not represent a future burden to the young [31], there is the possibility that they stimulate the haematophagous behaviour of adults. This could occur because larvae feed off the undigested blood excreted by adults, such that increased haematophagous behaviour of adults could increase the larval food source. In this case, abundance could indirectly influence parasite burden. Potential noninsect ectoparasites (Acari) were not entered in these analyses as their prevalence was very low (see Section 3 ) and identification was only possible to order level, such that the ecology of the individuals (parasitic or scavenging), and thus their impact, was unclear.

\section{Results}

3.1. Ectoparasite Abundance. Several ectoparasitic species were extracted from great tit nests. These included, in order of prevalence, adult and larval hen fleas (Ceratophyllus gallinae; Siphonaptera: Ceratophyllidae) in 95\% of nests, biting lice (Mallophaga: Ischnocera) in 55\% of nests, haematophagous blowfly (Protocalliphora spp.; Diptera: Calliphoridae) larvae and pupae in $45 \%$ of nests, together with ticks and haematophagous mites (Acari) in 15\% and 5\% of nests, respectively. The time in the breeding season was an important influence on nest ectoparasite community: blowfly larvae were present in $90 \%$ of late nests (i.e., those started after the median date of nest commencement), but absent from early nests (i.e., those started before the median date of nest commencement). This has been seen before [8] and reinforced the importance of controlling for time in the breeding season during nestbox pairing.

The number of individual ectoparasites in the nests was high: up to 1,275 individuals were found in one nest (including nonparasitic life stages). There was, however, considerable variability in nest parasitic load, both overall and for individual species (Figure 1). The number of adult hen fleas per nest ranged from 5 to 119 (mean $=35.7 \pm 7.5 \mathrm{SEM})$ while the number of lice varied from 0 to 25 (mean $=5.2 \pm 3.2$ SEM). The number of blowfly larvae was generally low (0-4 


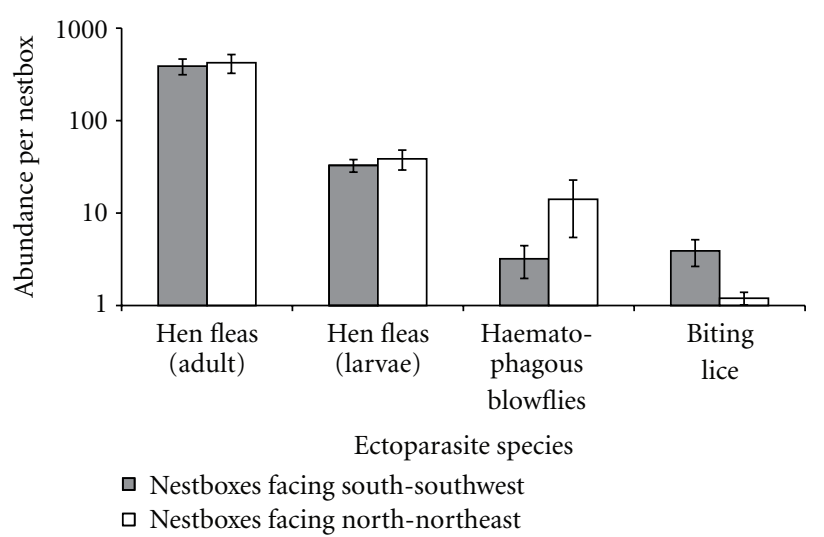

Figure 1: Mean ectoparasite abundance per nest according to nestbox orientation $($ error bars $=$ SEM $)$.

individuals per nest), but there were some extreme outliers of up to 135 individuals per nest.

Surprisingly, there was no relationship between the number of chicks (range 3 to 8 ) and either total ectoparasite abundance ( $r=0.145, N=20, P=0.542)$ or the abundance of any individual species $(P>0.05$ in all cases; tests not shown). No relationships were found between the abundance of different ectoparasitic species in the nests (i.e., the abundance of one species did not appear to influence the abundance of other species; $P>0.05$ in all cases; tests not shown). The only significant relationship was between different life stages of the same species: the number of adult hen fleas positively correlated, and intuitively, with the number of larvae $(r=0.756$, $N=19, P<0.001)$.

3.2. Ectoparasite Abundance and Orientation. Despite nestbox internal temperature correlating with orientation (circular-linear correlation $r=0.928, n=11200, P<0.001$; [32]), with nestboxes facing southwest being warmer than boxes facing northeast (Figure 2 (taken from [32])), there was no difference in the overall abundance of ectoparasites between boxes facing south-southwest and north-northeast $(430 \pm 112$ SEM individuals per nest versus $528 \pm 164$ SEM resp.; $t=0.502$, d.f. $=18, P=0.622$ ). Similarly, there was no difference in abundance of the two main haematophagous ectoparasites (adult hen fleas and larval blowflies) between boxes facing south-southwest and those facing north-northeast $(32.80 \pm 7.21$ SEM individuals per nest versus $42.90 \pm 14.40 \operatorname{SEM}(t=0.659$, d.f. $=18, P=0.518)$; $3.20 \pm 1.75$ SEM individuals per nest versus $15.67 \pm 13.56$ SEM $(t=0.962$, d.f. $=18, P=0.349)$, resp.). Any (albeit nonsignificant) differences in the abundance of these ectoparasites in relation to orientation were biased towards higher numbers in boxes facing north-northeast, rather than south-southwest as hypothesised (Figure 1). The apparently higher abundance of lice (Ischnocera) in boxes facing southsouthwest compared with those facing north-northeast $(3.90 \pm 1.77$ SEM versus $1.32 \pm 0.42$ SEM $)$ was nonsignificant $(t=1.631$, d.f. $=18, P=0.120)$.

3.3. Ectoparasite Abundance and Avian Offspring Condition. None of the four full MLRs undertaken (regressing the

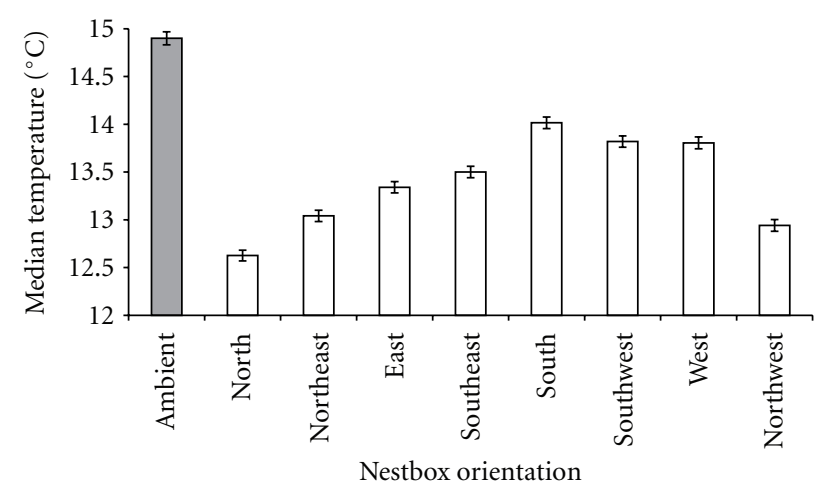

Figure 2: Mean internal nestbox temperatures according to orientation. Measurements were taken during the hottest part of the day (13.00-17.00 BST) during the 2006 breeding season $(n=12,600$ datapoints). Error bars $=$ SEM.

dependent variables wing length and relative mass against the ectoparasite load per chick and per nest) was significant or explained much variance $\left(P>0.275\right.$ and adjusted $R^{2}<0.081$ in all cases; Table 1). Reduced models could not be created since none of the candidate variables (individual ectoparasite species) resulted in an AIC change of $>2$ in the model parameters upon entry due to their lack of explanatory power [28]. Similarly, none of the variables entered in the GLMM analyses (adult hen fleas, larval hen fleas, blowflies, or biting lice) was significant; overall models were also insignificant (Table 2). The overall power of these models was sufficient to detect reasonably small effects of parasitism on offspring condition (80\% power to detect significance at $\alpha 0.05$ with an effect size of 0.346 (equivalent to an adjusted $r^{2}$ value of $0.118)$ ). This is considerably lower than effects sizes found in previous bird-parasite studies (e.g., $[8,13,33]$ ), and suggests that nonsignificance is not due to comparatively small sample sizes leading to a Type II error. Thus there is no evidence that ectoparasites are related to great tit offspring condition in this population.

\section{Discussion}

4.1. Ectoparasite Diversity. The prevalence of ectoparasites at Nagshead is similar to that found in other studies, for example, the $95 \%$ prevalence of hen fleas found here is comparable to the $93 \%$ prevalence in a meta-analysis of 2,668 (nonspecies-specific) avian nests [34]. The lack of any significant relationship between overall ectoparasite load and brood size agrees with a study on parasites in house sparrows (Passer domesticus) nests in America [33] and a study on hen fleas in great tit nests in Switzerland [17].

4.2. Ectoparasite Abundance and Orientation. Despite significantly higher temperatures in southwest-facing boxes, there was no difference in ectoparasite abundance relative to orientation. Thus it appears unlikely that boxes with increased internal temperatures are simultaneously less-preferred and associated with lower offspring condition (a situation that is contrary to the findings of other studies in temperate latitudes [35]), because of temperature-related differences 
TABLE 1: Results of multiple linear regression analyses between insect ectoparasite abundance (quantified per nest or per chick) and great tit offspring condition quantified using two condition-related traits (d.f. $=19$ in all cases).

\begin{tabular}{lcccc}
\hline Condition-related trait & \multicolumn{2}{c}{ Insect ectoparasites (per nest) } & \multicolumn{2}{c}{ Insect ectoparasites (per chick) } \\
& Adjusted $R^{2}$ & $P$ & Adjusted $R^{2}$ & 0.068 \\
\\
\hline Relative mass & 0.081 & 0.275 & 0.001 & 0.299 \\
Wing length & 0.000 & 0.694 & 0.678 \\
\hline
\end{tabular}

TABLE 2: GLMM analyses of ectoparasite abundance (divided into quartiles) and great tit offspring quality ( $n=93$ chicks in 20 nests).

\begin{tabular}{lccr}
\hline & & Wing length & \multicolumn{1}{c}{ Relative mass } \\
& $F$ & $P$ & $F$ \\
\hline Adult hen fleas (Ceratophyllus gallinae) & 0.154 & 0.924 & 0.187 \\
Larval hen fleas (C. gallinae) & 0.313 & 0.816 & 1.634 \\
Blowfly larvae (Protocalliphora spp.) & 0.7621 & 0.547 & 1.437 \\
Lice (Mallophaga: Ischnocera) & 1.316 & 0.336 & 0.262 \\
\hline
\end{tabular}

in ectoparasite load. The lack of any relationship between ectoparasite abundance and orientation suggests that the nonuniform nestbox selection with relation to orientation is not a behavioural response to avoid nest sites with high ectoparasite loads. This is contrary to research by George [22], who found the abundance of hen fleas to be higher in pied flycatcher boxes oriented south-southwest compared with north-northeast. However, George's conclusions, on a different avian species, were based on a comparison of very few nestboxes (eight boxes facing south-southwest with two facing north-northeast in 1956) and made without the application of inferential statistics.

It should be noted that the between-season removal of nesting material from nestboxes at many sites, including the study site, means that nestbox ectoparasite load is usually lower than in natural cavities $[36,37]$. Data on the magnitude of this difference are lacking for great tits; however, Pinkowski's [38] study of eastern bluebird (Sialia sialis) nests suggests that parasite-infested natural cavities may have, on average, twice as many ectoparasites as parasitised nestboxes, while the abundance of hen fleas was an order of magnitude lower in natural cavities than nestboxes in the case of marsh tits (Poecile palustris) [39]. Thus, it remains possible that there are orientation-related differences in ectoparasite load in natural cavities that have not been replicated in nestboxes. In this case, the avoidance of nestboxes facing south-southwest could be an evolutionary hangover [7]: effectively a "ghost of parasitism past." Crucially, however, this would not explain the reduced nestling condition observed in nestboxes facing south-southwest [21], only the parental avoidance of those boxes. Unless parasite load correlates with both orientation and offspring condition (see below), it is unlikely to be the proximate cause of directional nest-site choice.

4.3. Ectoparasite Abundance and Avian Offspring Condition. By definition, parasites should reduce the fitness of their host [40]. The lack of correlation between avian offspring condition and ectoparasite load found here is not, however, unprecedented. Indeed, the absence of a (measurable) effect of parasitism agrees with studies in the USA on nestboxbreeding eastern bluebirds [41], work on chestnut-backed and mountain chickadees (Poecile rufescens and P. gambeli) parasitised by Protocalliphora [42], and research on tree swallows (Tachycineta bicolor) parasitised by hen fleas [27]. There are several possible, nonmutually exclusive, explanations for the lack of any relationship between nest ectoparasite load and avian offspring condition.

(1) Comparatively Low Ectoparasite Load. The lack of a measurable reduction in offspring condition might be explained by the number of ectoparasites [43]. However, although ectoparasite abundance here is low in comparison with natural nest sites, it is still higher than in other studies where a relationship between ectoparasite abundance and chick condition has been found (e.g., for house sparrows: [33]).

(2) Compensatory Responses. It is possible that physiological or behavioural compensatory responses are used to reduce the intensity of parasitism or buffer its impact [7, 17]. Examples of such responses include preening [44] and alteration of posture as found in several Hawaiian birds [45].

(3) Condition-Dependent Effects. Parasitism might only cause measurable detriment to condition when nestlings are under stress, for example, during food shortages $[30,38]$ or in poor weather conditions [46].

(4) Parental Cost. An adaptive increase in parental provisioning rates can reduce the impacts of parasitism in great tits parasitized by hen fleas [47]. Parents may also reduce the impact of ectoparasites by increasing nest sanitation [48] or through increased use of insecticidal herbs (not reported in the great tit, but seen in the closely related blue tit [49]). Such responses do, however, have an energetic cost and form an important part of the tradeoff between current and future reproduction [50]. Measuring change in parental body condition before and after nesting in relation to ectoparasite load would be an interesting area for further study. 
(5) Masked Fitness Cost. Finally, it remains possible that parasite-related fitness costs were masked by other factors affecting offspring condition such as heritable parental condition [51], breeding-related parameters such as hatching asynchrony [52], and the condition of the nest territory [53].

4.4. Implications of Findings and Future Research Directions. The results outlined here suggest that nonuniform patterns in great tit nest-site selection and offspring condition in relation to orientation cannot be explained by a relationship between ectoparasite load and the direction a nestbox faces (despite orientation influencing nestbox temperatures). It should be noted, however, that these findings are based on correlational, rather than experimental, evidence and that the sample sizes were necessarily fairly small (93 nestlings from 20 broods) given the small number of nests created in nestboxes facing south-southwest (the least preferred direction) and statutory restrictions on fieldwork. Given this, it is not possible to conclude definitely on any cause-consequence patterns and it does remain possible that this small sample size could have led to type II error (although the sample sizes are similar to those used in several previous studies where significant effects have been found (e.g, $[33,41])$ and power analysis suggested that the models had sufficient power to detect relatively small effects; data not shown). Further investigation of the potential for relationships between nest cavity orientation, ectoparasite load and offspring fitness, ideally using larger sample sizes and/or a more experimental approach, would be useful in furthering understanding, especially if these were conducted in different climatic areas where the relationship between cavity orientation and temperature, and the effect of temperature on parasite loads, might be different. It would also be beneficial to investigate other possibilities, such as an association between microbial load and orientation as a result of direction-related differences in temperatures, which might account for directional differences in nest-site selection and breeding success.

\section{Acknowledgments}

The authors thank RSPB staff and volunteers at Nagshead, Maurice Sabelis and Izabela Lesna for valuable parasitology comments, and two peer reviewers for feedback on our initial submission. S. L. Elliot is in receipt of a CNPq scholarship, no. 300920/2010-5.

\section{References}

[1] D. W. T. Crompton, "Birds as habitat for parasites," in BirdParasite Interactions: Ecology, Evolution and Behaviour, J. E. Loye and M. Zuk, Eds., pp. 253-270, Oxford University Press, Oxford, UK, 1997.

[2] P. Heeb, M. Kölliker, and H. Richner, "Bird-ectoparasite interactions, nest humidity, and ectoparasite community structure," Ecology, vol. 81, no. 4, pp. 958-968, 2000.

[3] J. E. Loye and S. P. Carroll, "Ectoparasite behavior and its effects on avian nest site selection," Annals of the Entomological Society of America, vol. 91, no. 2, pp. 159-163, 1998.
[4] A. P. Moller, "Effects of parasitism by a haematophagous mite on reproduction in the barn swallow," Ecology, vol. 71, no. 6, pp. 2345-2357, 1990.

[5] A. Oppliger, H. Richner, and P. Christe, "Effect of an ectoparasite on lay date, nest-site choice, desertion, and hatching success in the great tit (Parus major)," Behavioral Ecology, vol. 5, no. 2, pp. 130-134, 1994.

[6] S. Merino and J. Potti, "Pied flycatchers prefer to nest in clean nest boxes in an area with detrimental nest ectoparasites," Condor, vol. 97, no. 3, pp. 828-831, 1995.

[7] J. Moore, Parasites and the Behaviour of Animals, Oxford University Press, Oxford, UK, 2002.

[8] D. D. Roby, K. L. Brink, and K. Wittmann, "Effects of bird blowfly parasitism on eastern bluebirds and tree swallow nestlings," Wilson Bulletin, vol. 104, pp. 630-643, 1992.

[9] B. Chapman and J. George, "The effects of ectoparasites on cliff swallow growth and survival," in Bird-Parasite Interactions: Ecology, Evolution and Behaviour, J. E. Loye and M. Zuk, Eds., pp. 69-92, Oxford University Press, Oxford, 1991.

[10] L. A. Durden, K. J. Linthicum, and T. P. Monath, "Laboratory transmission of eastern equine encephalomyelitis virus to chickens by chicken mites (Acari: Dermanyssidae)," Journal of Medical Entomology, vol. 30, no. 1, pp. 281-285, 1993.

[11] G. Tomás, S. Merino, J. Moreno, and J. Morales, "Consequences of nest reuse for parasite burden and female health and condition in blue tits, Cyanistes caeruleus," Animal Behaviour, vol. 73, no. 5, pp. 805-814, 2007.

[12] Y. Warren, "Protocalliphora braueri (Diptera: Calliphoridae) induced pathogenesis in a brood of marsh wren (Cistothorus palustris) young," Journal of wildlife diseases, vol. 30, no. 1, pp. 107-109, 1994.

[13] H. Richner, A. Oppliger, and P. Christe, "Effect of an ectoparasite on reproduction in great tits," Journal of Animal Ecology, vol. 62, no. 4, pp. 703-710, 1993.

[14] K. Allander, "The effects of an ectoparasite on reproductive success in the great tit: a 3-year experimental study," Canadian Journal of Zoology, vol. 76, no. 1, pp. 19-25, 1998.

[15] S. Merino and J. Potti, "Mites and blowflies decrease growth and survival in nestling pied flycatchers," Oikos, vol. 73, no. 1, pp. 95-103, 1995.

[16] T. Wesolowski, "Host-parasite interactions in natural holes: marsh tits (Parus palustris) and blow flies (Protocalliphora falcozi)," Journal of Zoology, vol. 255, no. 4, pp. 495-503, 2001.

[17] P. Heeb, I. Werner, H. Richner, and M. Kölliker, "Horizontal transmission and reproductive rates of hen fleas in great tit nests," Journal of Animal Ecology, vol. 65, no. 4, pp. 474-484, 1996.

[18] G. Tomás, S. Merino, J. Martínez-De La Puente, J. Moreno, J. Morales, and E. Lobato, "Determinants of abundance and effects of blood-sucking flying insects in the nest of a holenesting bird," Oecologia, vol. 156, no. 2, pp. 305-312, 2008.

[19] I. Lesna, P. Wolfs, F. Faraji, L. Roy, J. Komdeur, and M. W. Sabelis, "Candidate predators for biological control of the poultry red mite Dermanyssus gallinae," Experimental and Applied Acarology, vol. 48, no. 1-2, pp. 63-80, 2009.

[20] A. E. Goodenough, D. P. Maitland, A. G. Hart, and S. L. Elliot, "Nestbox orientation: a species-specific influence on occupation and breeding success in woodland passerines," Bird Study, vol. 55, no. 2, pp. 222-232, 2008.

[21] A. E. Goodenough, A. G. Hart, and S. L. Elliot, "Variation in offspring quality with cavity orientation in the great tit," Ethology Ecology and Evolution, vol. 20, no. 4, pp. 375-389, 2008. 
[22] R. S. George, "Fleas from nests of the pied flycatcher and other species in the Forest of Dean," Bird Study, vol. 6, pp. 132-136, 1959.

[23] L. Svensson, Identification Guide to European Passerines, Svensson, Stockholm, Sweden, 4th edition, 1992.

[24] A. G. Gosler, J. J. D. Greenwood, J. K. Baker, and N. C. Davidson, "The field determination of body size and condition in passerines: a report to the British Ringing Committee," Bird Study, vol. 45, no. 1, pp. 92-103, 1998.

[25] D. H. Clayton and B. A. Walther, "Collection and quantification of arthropod parasites of birds," in Host-Parasite Evolution: General Principles and Avian Models, D. H. Clayton and J. Moore, Eds., pp. 419-440, Oxford University Press, Oxford, UK, 1997.

[26] C. A. Rogers, R. J. Robertson, and B. J Stutchbury, "Patterns and effects of parasitism by Protocalliphora sialia on tree swallow nestlings," in Bird-Parasite Interactions: Ecology, Evolution and Behaviour, J. E. Loye and M. Zuk, Eds., pp. 123-139, Oxford University Press, Oxford, UK, 1991.

[27] K. Thomas and D. Shutler, "Ectoparasites, nestling growth, parental feeding rates, and begging intensity of tree swallows," Canadian Journal of Zoology, vol. 79, no. 2, pp. 346-353, 2001.

[28] M. J. Crawley, Statistics: An Introduction Using R, John Wiley and Sons, New York, NY, USA, 2005.

[29] S. Hurtrez-Boussès, J. Blondel, P. Perret, and F. Renaud, "Relationship between intensity of blowfly infestation and reproductive success in a Corsican population of Blue Tits," Journal of Avian Biology, vol. 28, no. 3, pp. 267-270, 1997.

[30] A. Simon, D. Thomas, J. Blondel, P. Perret, and M. M. Lambrechts, "Physiological ecology of mediterranean blue tits (Parus caeruleus L.): effects of ectoparasites (Protocalliphora spp.) and food abundance on metabolic capacity of nestlings," Physiological and Biochemical Zoology, vol. 77, no. 3, pp. 492501, 2004.

[31] G. H. Harper, A. Marchant, and D. G. Boddington, "The ecology of the hen flea Ceratophyllus gallinae and the moorhen flea Dasypsyllus gallinulae in nestboxes," Journal of Animal Ecology, vol. 61, no. 2, pp. 317-327, 1992.

[32] A. E. Goodenough, Factors influencing nest-site choice and reproductive success in Cyanistes caeruleus (blue tit), Parus major (great tit) and Ficedula hypoleuca (pied flycatcher), Ph.D. thesis, University of Gloucestershire, UK, 2008.

[33] C. B. Weddle, "Effects of ectoparasites on nestling body mass in the House Sparrow," Condor, vol. 102, no. 3, pp. 684-687, 2000.

[34] F. Tripet and H. Richner, "Density-dependent processes in the population dynamics of a bird ectoparasite Ceratophyllus gallinae," Ecology, vol. 80, no. 4, pp. 1267-1277, 1999.

[35] D. R. Ardia, J. H. Pérez, and E. D. Clotfelter, "Nest box orientation affects internal temperature and nest site selection by Tree Swallows," Journal of Field Ornithology, vol. 77, no. 3, pp. 339-344, 2006.

[36] W. B. Rendell and N. A. M. Verbeek, "Old nest material in nest boxes of tree swallows: effects on nest-site choice and nest building," Auk, vol. 113, no. 2, pp. 319-328, 1996.

[37] K. L. Purcell, J. Verner, and L. W. Oring, "A comparison of the breeding ecology of birds nesting in boxes and tree cavities," Auk, vol. 114, no. 4, pp. 646-656, 1997.

[38] B. C. Pinkowski, "Blowfly parasitism of eastern bluebirds in natural and artificial nest sites," Journal of Wildlife Management, vol. 41, pp. 272-276, 1977.

[39] T. Wesolowski and M. Stanska, "High ectoparasite loads in hole-nesting birds_-a nestbox bias?" Journal of Avian Biology, vol. 32, no. 3, pp. 281-285, 2001.
[40] P. W. Price, Evolutionary Biology of Parasites, Princeton University Press, Princeton, NJ, USA, 1980.

[41] K. Wittman and R. C. Beason, "The effect of blowfly parasitism on nestling eastern bluebird development," Journal of Field Ornithology, vol. 63, pp. 286-293, 1992.

[42] C. S. Gold and D. L. Dahlsten, "Effects of parasitic flies (Protocalliphora spp.) on nestlings of mountain and chestnut-backed chickadees," Wilson Bulletin, vol. 95, pp. 560-572, 1983.

[43] H. Proctor and I. Owens, "Mites and birds: diversity, parasitism and coevolution," Trends in Ecology and Evolution, vol. 15, no. 9, pp. 358-364, 2000.

[44] A. Simon, D. W. Thomas, J. R. Speakman, J. Blondel, P. Perret, and M. M. Lambrechts, "Impact of ectoparasitic blowfly larvae (Protocattiphora spp.) on the behavior and energetics of nestling Blue Tits," Journal of Field Ornithology, vol. 76, no. 4, pp. 402-410, 2005.

[45] C. Van Riper, S. G. Van Riper, M. L. Goff, and M. Laird, "The epizootiology and ecological significance of malaria in Hawaiian land birds," Ecological Monographs, vol. 56, pp. 327334, 1986.

[46] R. Dufva and K. Allander, "Variable effects of the hen flea Ceratophyllus gallinae on the breeding success of the great tit Parus major in relation to weather conditions," Ibis, vol. 138, no. 4, pp. 772-777, 1996.

[47] P. Christe, H. Richner, and A. Oppliger, "Begging, food provisioning, and nestling competition in great tit broods infested with ectoparasites," Behavioral Ecology, vol. 7, no. 2, pp. 127131, 1996.

[48] F. Tripet, M. Glaser, and H. Richner, "Behavioural responses to ectoparasites: time-budget adjustments and what matters to Blue Tits Parus caeruleus infested by fleas," Ibis, vol. 144, no. 3, pp. 461-469, 2002.

[49] C. Petit, M. Hossaert-McKey, P. Perret, J. Blondel, and M. M. Lambrechts, "Blue tits use selected plants and olfaction to maintain an aromatic environment for nestlings," Ecology Letters, vol. 5, no. 4, pp. 585-589, 2002.

[50] H. Richner and F. Tripet, "Ectoparasitism and the trade-off between current and future reproduction," Oikos, vol. 86, no. 3, pp. 535-538, 1999.

[51] H. Wendeln and P. H. Becker, "Effects of parental quality and effort on the reproduction of common terns," Journal of Animal Ecology, vol. 68, no. 1, pp. 205-214, 1999.

[52] M. J. Stenning, "Hatching asynchrony, brood reduction and other rapidly reproducing hypotheses," Trends in Ecology and Evolution, vol. 11, no. 6, pp. 243-246, 1996.

[53] R. Przybylo, D. A. Wiggins, and J. Merilä, "Breeding success in Blue Tits: good territories or good parents?” Journal of Avian Biology, vol. 32, no. 3, pp. 214-218, 2001. 

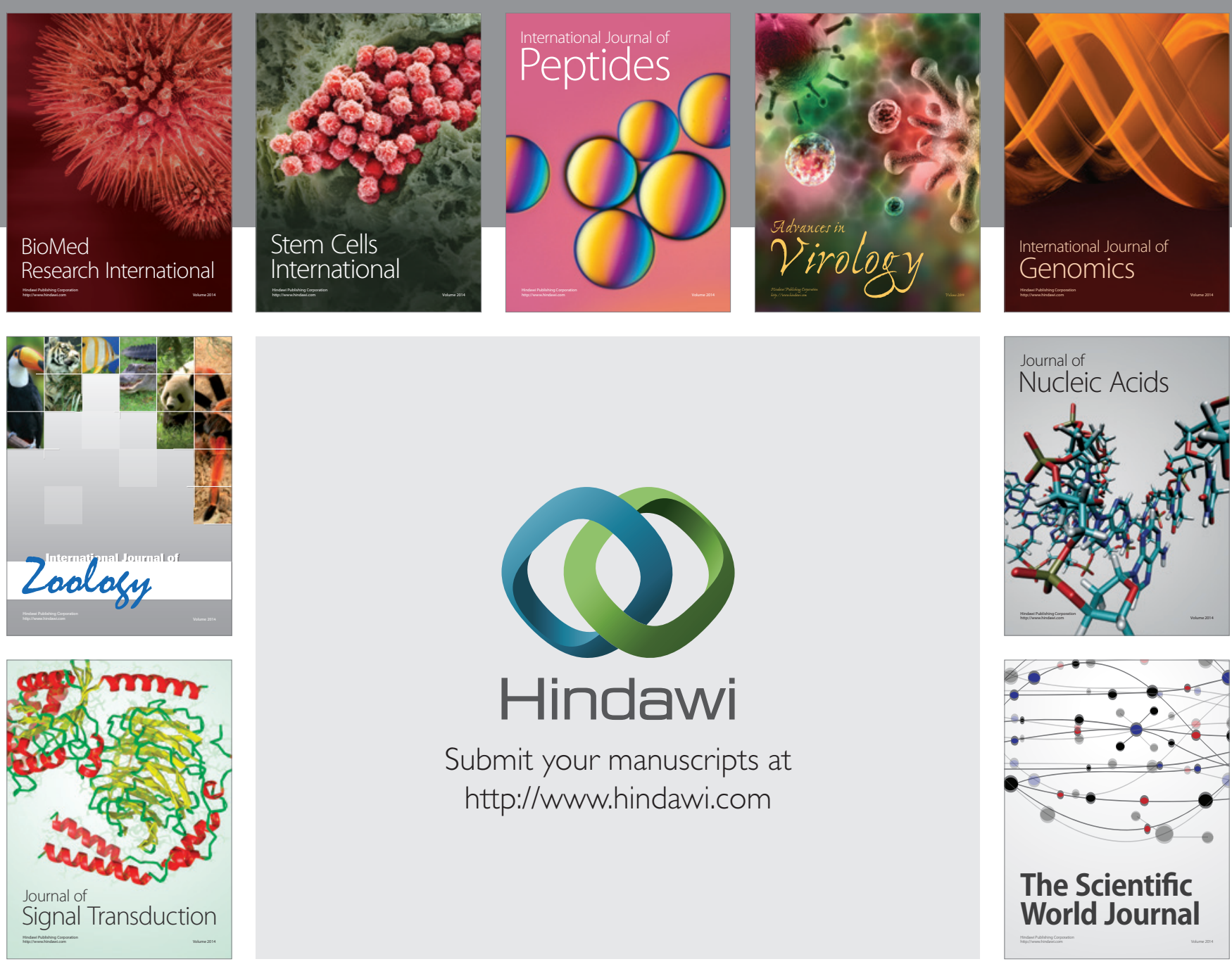

Submit your manuscripts at

http://www.hindawi.com
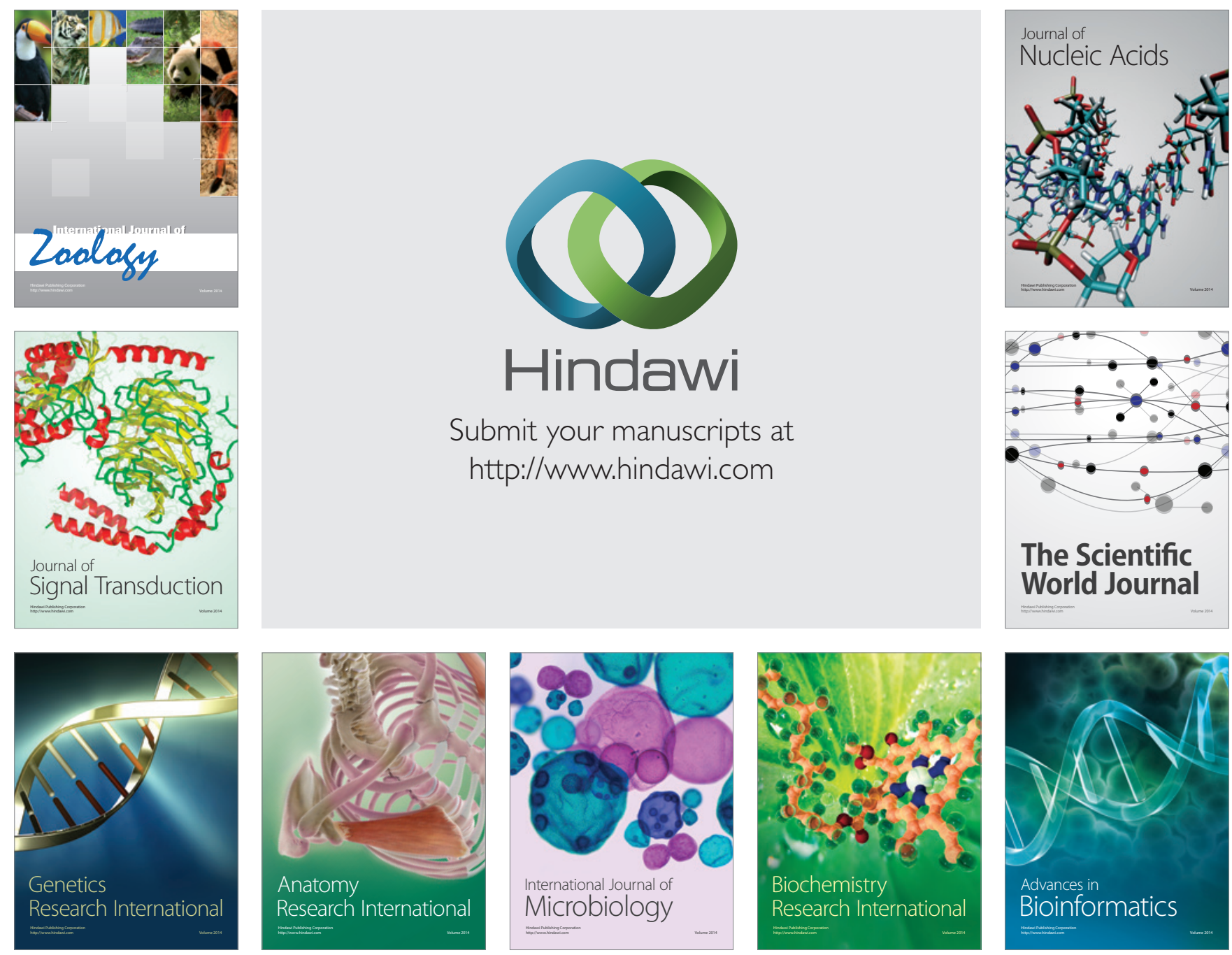

The Scientific World Journal
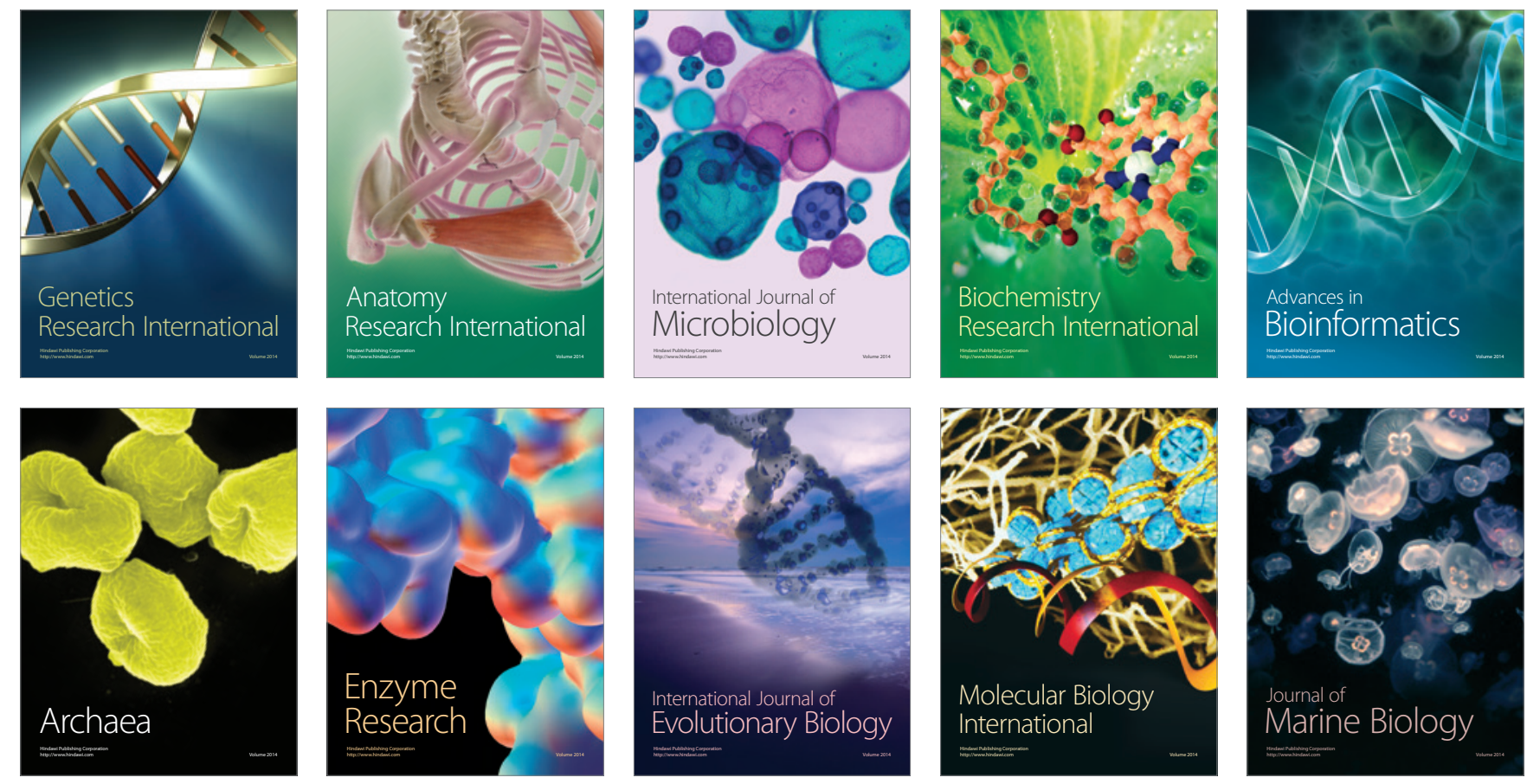